\title{
EVALUASI KINERJA PROGRAM PENGEMBANGAN SAPI POTONG BANTUAN DINAS PERTANIAN DAN KEHUTANAN KOTA KENDARI
}

\author{
Abdul Haadii ${ }^{1}$, Rahim Aka ${ }^{2}$, La ode Ba'a \\ ${ }^{1}$ AlumnI Jurusan Peternakan FPt UHO \\ ${ }^{2}$ Dosen Jurusan Peternakan FPt UHO \\ Email : rahim.aka05@gmail.com
}

\begin{abstract}
ABSTRAK
Salah satu upaya pengembangan sapi potong yang di lakukan oleh Dinas Pertanian dan Kehutanan Kota Kendari adalah pemberian bantuan kepada kelompok tani yang ada di Kota Kendari.Penelitian ini bertujuan untuk mengetahui perkembangan populasi sapi potong, permasalahan dan kebijakan pemerintah Kota Kendari dalam pengembangan peternakan sapi potong di Kota Kendari.Metode penelitian adalah sensus dan sampel ditentukan secara purposive yaitu Kecamatan Baruga, Poasia, Abeli, Puwatu dan Mandonga.Teknik pengumpulan data dilakukan melalui wawancara dan pengamatan langsung di lapangan. Hasil penelitian menunjukkan bahwa kelompok tani penerima bantuan hibah program pengembangan sapi potong tersebut terdiri dari 22 kelompok tani ternak dengan jumlah bantuan 10 ekor perkelompok. Pola pemeliharaan sapi potong di Kota Kendari umumnya dilakukan secara semi intensif $(92,3 \%)$, rata-rata perkembangan populasi sapi bantuan 24 ekor/tahun. Permasalahan pengembangan sapi potong yang dominan muncul dalam pengembangan sapi potong adalah musim kemarau sulit diperoleh hijauan makanan ternak, harga berfluktuasi, lahan penggembalaan sempit.Dukungan kebijakan yaitu peraturan daerah tentang peternakan dan kesehatan hewan. Hasil evaluasi program di lapangan dilaksanakan sesuai dengan petunjuk teknis program sehingga layak untuk dilanjutkan. Saran dari hasil penelitian ini adalah perlu adanya pengembangan lahan hijauan makanan ternak dan kelompok tani penerima bantuan sebaiknya diprioritaskan kepada kelompok tani yang memiliki lahan penggembalaan yang cukup luas untuk mengantisipasi kekurangan hijauan pada musim kemarau.
\end{abstract}

Kata kunci : Evaluasi kinerja program pengembangan, Sapi potong.

\begin{abstract}
One of the beef cattle development efforts doing by Agriculture and Forester Department of Kendari City was the granting of aid to farmers group that existed in Kendari City. This research aims to study the development of beef cattle population, problems, and Government policies on beef cattle development in Kendari City. This research using cencus and sample method that determined in purposive. The chosen location were Baruga, Abeli, Puwatu and Mandonga Subdistrict. The technique of data collection was done through interviews and direct observation in location. The result showed that 22 cattle farmer groups received the beef cattle development grant. Each group received 10 beef cattles. Beef maintenance system that use in Kendari was generally semi intensive $(92,3 \%)$, and the development average of beef cattle population was 24 cattles per year. The dominant problem appeared in beef cattle development were the diffulty of obtaining feed in dry season, price fluctuation, and the narrowness of development land. The supporting policies was local regulation about animal husbandry and animal health. The result of program evaluation showed that the program was carried out in accordance with its technical instruction so that it deserves to be continued. From the results, we recommend the development of forage land. Besides that, the farmer group recipient should preferably be prioritized to farmer groups who have ample grazing land in anticipation of forage shortages during dry season.
\end{abstract}

Key Words: Performance Evaluation of Development Program, Beef Cattle. 


\section{PENDAHULUAN}

Peternakan sapi potong merupakan salah satu bagian dari sub sektor pertanian yang perlu dikembangkan dan dimanfaatkan secara optimal. Dalam rangka pengembangan ternak sapi potong di Indonesia maka peranan keluarga dan kelompok petani peternak tidak dapat diabaikan namun perlu dibina dan ditunjang oleh pemerintah melalui pembangunan proyek-proyek peternakan sapi potong.

Pola pemeliharaan sapi potong di Sulawesi Tenggara umumnya masih dilakukan secara ekstensif dan semi intensif.Sedangkan pola pemeliharaan sapi potong di Kota Kendari umumnya dilakukan secara semi intensif. Pola pemeliharan ekstensif adalah sistem pemeliharaan ternak sapi potong yang dilepas begitu saja di padang penggembalaan. Pola pemeliharaan semi intensif adalah sistem pemeliharaan ternak sapi potong dimana pada malam hari dikandangkan dan pagi sampai sore hari dilepas di padang penggembalaan.

Kota Kendari merupakan salah satu kota di Provinsi Sulawesi Tenggara mempunyai lahan beragam meliputi padang rumput $27 \%$, sawah $15 \%$ dan tegal/kebun $10 \%$ (BPS Kota Kendari, 2009).Potensi lahan tersebut mempunyai dampak pada pola penggunaan dan pengolahan lahan pertanian, hasil pertanian serta ketersedian pakan ternak sehingga berpotensi untuk pengembangan peternakan sapi potong.

Jenis ternak ternak yang dikembangkan di Kota Kendari terdiri dari ternak besar, ternak kecil dan ternak unggas. Populasi ternak sapi di Kota Kendari tahun 2009 adalah 2.173 ekor dan ternak kambing adalah 3.123 ekor. Populasi ternak sapi di Kota Kendari tersebar di Kecamatan Baruga, Poasia, Abeli, Puwatu dan Mandonga.

Untuk mensukseskan program swasembada daging 2014 dan mengatasi penurunan populasi sapi potong di Kota
Kendari, maka salah satu kebijakan dan program yang dilakukan yang dilakukan oleh Dinas Pertanian dan Kehutanan Kota Kendari adalah bantuan sapi potong, hijauan makanan ternak (HMT), fasilitas kandang, vaksin dan obat-obatan. Semua bantuan program tersebut diberikan kepada kelompok tani yang ada di Kota Kendari melalui seleksi yang dinamakan dengan calon petani calon lokasi (CPCL).Program bantuan yang dilakukan oleh Dinas Pertanian dan Kehutanan Kota Kendari kepada kelompok tani tersebut sudah berlangsung sejak tahun 2006 sampai dengan tahun 2010.

Untuk mengetahui kinerja dari program pengembangan sapi potong di Kota Kendari yang dilakukan oleh Dinas Pertanian dan Kehutanan Kota Kendari maka perlu dilakukan penelitian tentang Evaluasi Kinerja Program Pengembangan Sapi Potong Bantuan Dinas Pertanian dan Kehutanan Kota Kendari karena sampai sekarang belum ada yang melakukan penelitian tersebut.

\section{MATERI DAN METODE}

Penelitian ini dilaksanakan pada bulan April - Mei 2011, di Kota Kendari yang meliputi 5 (lima) kecamatan yaitu Kecamatan Baruga, Poasia, Abeli, Puwatu dan Mandonga.

Populasi dalam penelitian ini adalah semua kelompok tani yang ada di Kota Kendari yang mendapat bantuan sapi potong dari Dinas Pertanian dan Kehutanan Kota Kendari. Sampel penelitian adalah kelompok tani penerima bantuan berjumlah 22 kelompok yang ada di lima kecamatan yaitu Kecamatan Baruga, Poasia, Abeli, Puwatu, Mandonga dan setiap kepala BPP yang ada di 5 (lima) kecamatan tersebut serta Kepala Bidang Peternakan Dinas Pertanian dan Kehutanan Kota Kendari.

Metode penentuan lokasi penelitian dilakukan secara purposive sampling yaitu di wilayah Kecamatan Baruga, Poasia, Abeli, Puwatu dan Mandonga dan penentuan kelompok tani (responden) 
sebagai sampel penelitian adalah menggunakan metode sensus.

Jenis data yang dikumpulkan pada penelitian ini terbagi atas dua yaitu data primer dan data sekunder.Data primer adalah data yang diperoleh dari responden, Kepala Bidang Peternakan Dinas Pertanian dan Kehutanan Kota Kendari dan Kepala BPP. Data primer diperoleh dengan cara wawancara langsung menggunakan kuisioner dan pengamatan langsung di lapangan, sedangkan data sekunder adalah data yang diperoleh dari Dinas Pertanian dan Kehutanan Kota Kendari, BPP di Kota Kendari dan BPS Kota Kendari.

Variabel yang diamati pada penelitian adalah :

a. Dinamika kelompok ternak yang meliputi karakteristik kelompok tani penerima bantuan, dan jenis bantuan.

b. Manajemen pemeliharaan ternak sapi yang meliputi pakan HMT, perkandangan, pencegahan dan penanggulangan penyakit.

c. Perkembangan jumlah ternak bantuan

d. Pemasaran

e. Permasalahan pengembangan sapi potong di Kota Kendari

f. Kebijakan pemerintah Kota Kendari

g. Evaluasi

Data yang diperoleh baik berupa data primer maupun data sekunder ditabulasi dan dianalisis, secara deskriptif.

\section{HASIL DAN PEMBAHASAN}

\section{A. Dinamika Kelompok Tani}

Gerungan (1986) mengatakan dinamika kelompok adalah analisis dari hubungan-hubungan kelompok sosial yang berdasarkan prinsip bahwa tingkah laku dalam kelompok itu adalah hasil dari interaksi yang dinamis antara individuindividu dalam situasi sosial.

Kelompok tani ternak sapi di Kota Kendari berjumlah 22 kelompok yang terdapat di Kecamatan Puwatu, Mandonga, Baruga, Poasia dan Abeli. Berdasarkan wawancara dengan para ketua kelompok tani ternak bahwa setiap kelompok dalam setiap orang mendapatkan 2 ekor ternak sapi yaitu jantan 1 ekor dan betina 1 ekor atau 2 ekor betina per orang. Selain itu setiap Kelompok tani penerima bantuan aktif melakukan pertemuan kelompok yang dilakukan seminggu sekali berdasarkan jadwal pertemuan kelompok yang telah disepakati dan dihadiri oleh PPL setempat atau instansi terkait. Melalui pertemuan kelompok tani tingkat interaksi/komunikasi antar peternak maupun penyuluh atau instansi terkait, lebih efisien sehingga penyampaian informasi lebih mudah guna meningkatkan pengetahuan, keterampilan dan sikap yang berhubungan dengan manajemen pemeliharaan yaitu teknologi pakan, manajemen dan teknologi reproduksi, tatalaksana perkandangan, pengendalian penyakit dan perbaikan aspek kelembagaan.

\section{Persyaratan Kelompok Tani Penerima Bantuan}

Berdasarkan hasil wawancara dengan perternak sapi potong diperoleh gambaran bahwa syarat untuk mendapatkan bantuan adalah harus memiliki kelompok tani, memiliki lahan untuk beternak, memiliki kandang dan mengajukan permohonan berupa proposal untuk mendapatkan bantuan serta diusulkan oleh Penyuluh Pertanian setempat. Sedangkan menurut Murdiantoro dan Samsiah Dahri mengatakan bahwa syarat untuk mendapatkan bantuan sapi potong adalah memiliki kelompok tani dan terdaftar di Kantor Balai Penyuluhan Pertanian, Perikanan dan Kehutanan (BP3K), mengajukan proposal permohanan bantuan sapi potong, memiliki lahan yang jelas status kepemilikannya dan berpotensi untuk pengembangan sapi potong, memiliki kandang, serta diajukan oleh Penyuluh Pertanian setempat dalam bentuk CPCL (Calon Petani Calon Lokasi). 


\section{Jenis Bantuan}

Jenis bantuan yang diberikan Pemerintah Kota Kendari melalui Dinas Pertanian dan Kehutanan Kota Kendari kepada peternak sapi potong adalah hibah yang dinamakan program pengembangan sapi potong yang diberikan langsung kepada masyarakat yakni kelompok tani ternak sapi potong.

Adanya program bantuan sapi potong kepada kelompok tani ternak yang diberikan oleh pemerintah diharapkan memberikan dampak positif terhadap pengembangan sapi potong di Kota Kendari baik dari sisi peningkatan populasi, pendapatan maupun lapangan kerja baru. Berdasarkan wawancara dengan responden diperoleh informasi, selain memelihara ternak sapi peternak juga mengolah limbah ternak berupa kotoran ternak untuk pupuk dengan tingkat pendapatan perbulan Rp 300.000, dan juga digunakan untuk biogas dalam skala rumah tangga

\section{B. Manajemen Pemeliharaan Ternak Sapi}

Pola pemeliharaan akan mempengaruhi kondisi ternak, yakni melindungi ternak sapi potong dari: (1) iklim, (2) gangguan penyakit, dan (3) gangguan keamanan seperti pencurian (Gunawan, 1998).

Pemeliharaan sapi potong di Kota Kendari umumnya dilakukan secara semi intensif $(94,5 \%)$ dan ekstensif $(5,5 \%)$ yakni pagi hari dilepas dan pada saat menjelang petang di kandangkan, hal ini dapat dilihat pada Tabel 1.

Tabel 1. Pola Pemeliharaan Ternak Sapi Potong di Kota Kendari

\begin{tabular}{lcc}
\hline Pola Pemeliharaan & $\begin{array}{c}\text { Jumlah Peternak } \\
(\text { Orang) }\end{array}$ & $\begin{array}{c}\text { Persentase } \\
(\%)\end{array}$ \\
\hline Intensif & - & 0 \\
Semi Intensif & 105 & 94,5 \\
Ekstensif & 5 & 5,5 \\
\hline \multicolumn{1}{c}{ Jumlah } & 110 & 100 \\
\hline
\end{tabular}

Berdasarkan data pada Tabel 5, dapat dilihat pola pemeliharaan ternak sapi di Kota Kendari adalah pola pemeliharaan semi intensif $(94,5 \%)$ dan pemeliharaan secara ekstensif $(5,5 \%)$. Jadi sebagian besar pola pemeliharaan ternak sapi potong di Kota Kendari adalah semi intensif. Hal ini disebabkan bahwa Kendari merupakan wilayah perkotaan yang didominasi pemukiman pen duduk, perkantoran, pusat perbelanjaan dan fasilitas umum lainnya sehingga ketersediaan lahan untuk penggembalaan ternak semakin sedikit.

\section{Hijauan Makanan Ternak (HMT)}

Berbagai faktor dalam usaha pertanian menuntut agar pemberian makanan untuk ternak memenuhi syarat minimal (Parakkasi, 1998).Makanan ternak berupa pakan hijauan dapat dikelompokkan menjadi dua macam, yakni jenis rumput-rumputan dan jenis daundaunan.Rumput-rumputan umumnya memiliki kandungan karbohidrat relatif tinggi berupa rumput lapangan dan jenis daun-daunan yang dapat dimanfaatkan untuk pakan sapi adalah daun waru, daun intaran dan daun dadap (Guntoro, 2002).

Penyedian hijaun makanan ternak (HMT) di Kota Kendari berupa rumput alam/padang penggembalaan dan sisa atau limbah pertanian.Rumput alam/padang penggembalaan yang ada di Kota Kendari berdasarkan hasil penelitian diperoleh rumput yang diberikan berupa rumput gajah sedangkan limbah pertanian yang diberikan yakni daun jagung, kulit jagung, kulit pisang, sisa sayuran dan sagu. 


\section{Perkandangan}

Kandang berfungsi sebagai tempat naungan, produksi dan reproduksi, tempat merawat ternak yang sakit dan mempermudah pengontrolan ternak. Secara umum, ada dua tipe sistem kandang ternak sapi yakni (1) Kandang individu, tipe kandang ini dapat memacu pertumbuhan yang lebih cepat karena tidak terjadi kompetisi dalam mendapatkan pakan dan memiliki ruang gerak yang tidak terbatas sehingga energi yang diperoleh dari asupan pakan digunakan untuk hidup pokok dan produksi daging tidak hilang, (2) Kandang kelompok, terjadi kompetisi dalam mendapatkan pakan sehingga sapi yang kuat cenderung cepat tumbuh dari pada sapi yang lemah (Abidin, 2006).

Berdasarkan hasil wawancara dengan responden bahwa semua kelompok tani penerima bantuan sapi potong memiliki kandang. Jenis kandang yang dimiliki oleh kelompok tani penerima bantuan tersebut yaitu kandang kelompok.

\section{Pencegahan dan Penanggulangan Penyakit}

Penyakit menular timbul karena serangan jasad renik atas tubuh hewan.Kebanyakan jasad renik ini mengeluarkan racun (toksin), yang tentu saja merusakan jaringan tubuh penderita (sapi potong), menghancurkan alat-alat tubuh dan menimbulkan kematian.Jasad renik tadi pada umumnya masuk ke dalam tubuh hewan melalui lubang-lubang tubuh, seperti mulut, hidung, alat kelamin, kulit yang luka, lecet atau akibat gigitan serangga dan kutu.Beberapa penyakit yang diderita oleh sapi potong diantaranya adalah penyakit mulut, surra, radang paha, keguguran, dan bloat (kembung) (Sugeng, 2003).

Jenis penyakit yang sering menyerang ternak sapi bantuan dilokasi penelitian adalah penyakit kembung perut, mata, lumpuh, caplak dan cacingan.Jumlah ternak sapi bantuan yang mati sebanyak 10 ekor.Kematian ternak sapi tersebut disebabkan keracunan dan penyakit cacing. Penanggulangan penyakit yang menyerang sapi potong di Kota Kendari diatasi dengan menggunakan obat-obatan seperti gusanex untuk mengatasi luka dan mencegah gangguan lalat, vet-oxy sebagai antibiotik, verm-o untuk mengatasi penyakit cacing, Timpanol, Anthystamin untuk mengatasi keracunan. Penanggulangan penyakit dilakukan oleh Dokter hewan dan Petugas Peternakan yang berada ditiap Kecamatan berdasarkan laporan responden maupun PPL setempat.

\section{Jumlah Ternak Bantuan}

Sistem pemeliharaan ternak sapi yang baik akan memberikan efek yang baik pula terhadap pertumbuhan populasi dan peningkatan mutu ternak sapi yang dihasilkan. Populasi sapi bantuan diberikan sejak tahun 2006-2009 oleh pemerintah kepada kelompok tani di Kota Kendari cenderung terjadi pertambahan populasi yaitu rata-rata 24 ekor/tahun dan dapat dilihat pada Tabel 2.

Tabel 4.Perkembangan JumlahTernak bantuan pada tahun 2011

\begin{tabular}{ccccc}
\hline $\begin{array}{c}\text { Sapi } \\
\text { Bantuan } \\
\text { Tahun }\end{array}$ & $\begin{array}{c}\text { Ternak } \\
\text { Awal } \\
\text { (Ekor) }\end{array}$ & $\begin{array}{c}\text { Ternak } \\
\text { Akhir } \\
\text { (Ekor) }\end{array}$ & $\begin{array}{c}\text { Perkembangan } \\
\text { ternak } \\
\text { tahun 2011 (Ekor) }\end{array}$ & $\begin{array}{c}\text { Rata-rata } \\
\text { perkembangan } \\
\text { ternak/tahun (\%) }\end{array}$ \\
\hline 2006 & 20 & 34 & 14 & 18,6 \\
2007 & 50 & 80 & 30 & 18,5 \\
2008 & 110 & 177 & 67 & 23,6 \\
2009 & 40 & 51 & 11 & 27,5 \\
\hline Jumlah & 220 & 342 & 122 & 88,2 \\
\hline Rata-rata & & & 24 & 22 \\
\hline
\end{tabular}


Berdasarkan Tabel 4, maka peningkatan populasi tersebut cukup rendah yaitu rata-rata $22 \%$ per tahun. Rendahnya rata-rata pertumbuhan populasi sapi bantuan tersebut disebabkan oleh sebagian besar sapi bantuan yang diberikan kepada kelompok tani adalah sapi yang berumur 1-2 tahun.Keadaan tersebut menyebabkan sapi-sapi bibit bantuan belum bisa melahirkan anak pada tahun pertama pemeliharaan, nanti setelah 2 tahun pemeliharaan sapi-sapi bibit sudah melahirkan anak.

\section{Pemasaran}

Penerimaan dalam usahatani memegang peranan sangat penting bagi petani dalam kelanjutan usahataninya, di mana besar kecilnya penerimaan dari usahatani akan mempengaruhi besar kecilnya pendapatan. Penerimaan usahatani meliputi produk total usahatani mencakup produk yang dijual, dikomsumsi rumah tangga petani untuk pembayaran dan disiapkan pada akhir tahun (Soekartawi, 2011).

Dari segi ekonomi, ciri yang sangat penting pada petani kecil adalah terbatasnya sumberdaya dasar tempat ia berusahatani (Soekartawi, 2011). Keterbatasan lahan yang dimiliki oleh peternak di Kota Kendari maka penjualan sapi dilakukan ketika ada yang datang membeli untuk hajatan atau menjelang hari-hari besar keagamaan seperti Idul Adha permintaan meningkat.

Penjualan ternak sapi bantuan yang dilakukan oleh anggota kelompok tani yaitu pada tahun 2010 dan tahun 2011 sebanyak 90 ekor dengan kisaran harga Rp. 6.000.000 - Rp. 8.000.000 per ekor. Selanjutnya dari hasil penjualan tersebut sebagian digunakan kembali untuk membeli ternak sapi dengan harga kisaran Rp. 3.000.000 - Rp 4.000.000 per ekor sebanyak 43 ekor.

Pemasaran ternak sapi di Kota Kendari berdasarkan hasil wawancara adalah biasanya para pedagang mencari peternak yang menjual sapinya.Pembeli datang langsung ketempat pemilik sapi dan biasanya adalah pedagang perantara. Adapun peternak yang menjual sapinya langsung kepada konsumen akhir adalah pada saat-saat tertentu dimana saat ada acara hajatan atau menjelang hari-hari besar keagamaan.

\section{E. Permasalahan Pengembangan Sapi Potong}

Sapi potong di Kota Kendari memiliki permasalahan dalam pengembangannya. Berdasarkan hasil wawancara dengan responden, permasalahan yang dominan muncul dalam pengembangan sapi potong adalah musim kemarau sulit diperoleh hijauan makanan ternak, harga ternak berfluktuasi, lahan penggembalaan sempit, seringnya ternak diserang penyakit cacing dan mata serta tingkat keamanan.

\section{F. Program dan Kebijakan Pemerintah Kota Kendari}

Program pemerintah Kota Kendari dalam rangka mendukung pengembangan sapi potong berdasarkan hasil wawancara dengan Murdiantoro (Kabid Peternakan Dinas Pertanian dan Kehutanan Kota Kendari, sebagai informan) adalah :

1. Rumah potong hewan (RPH) di Kota Kendari dapat meminimalkan pemotongan betina produktif dan menjaga hak-hak ternak dalam pemotongannya, sehingga didapatkan daging yang ASUH (aman, sehat, utuh dan halal).

2. Pembagunan Poskeswan memberikan arti yang signifikan buat pemeriksaan kesehatan ternak.

3. Bantuan sapi bibit

4. Pelatihan Budidaya Ternak Sapi potong Bagi Petugas dan Peternak

5. Pelatihan Biogas bagi Petugas dan Peternak

6. Pengembangan HMT

7. Pengadaan Alat dan Obat Ternak

8. Satu Kelurahan Satu Penyuluh

9. Satu Kecamatan Satu Petugas Peternakan 
10. Penjaringan sapi Betina Produktif

11. Pembangunan Instalasi Biogas

12. Program pengendalian penyakit ternak.

RPH (Rumah Potong Hewan) di

Kota Kendari 1 (Unit) yang berada di

Kelurahan Anggoeya Kecamatan Poasia

Kota Kendari yang peresmiannya dilakukan pada tahun 2001.

Pembangunan Poskeswan akan di laksanakan pada tahun 2012 sebanyak 1 (Satu) Unit yang akan dibangun di Kelurahan Matabubu, Kecamatan Poasia Kota Kendari.

Bantuan sapi bibit diberikan kepada kelompok tani melalui tahapan seleksi yang dilakukan oleh Dinas Pertanian dan Kehutanan Kota Kendari dan Balai Penyuluhan Pertanian berdasarkan aturan yang sudah ditetapkan.

Pelatihan budidaya ternak sapi potong bagi Petugas dan Peternak dilaksanakan ketika ada kegiatan Program Pengembangan Sapi Potong.Jadi Pelatihan ini dilakukan sejak tahun 2006-2009 dalam rangka meningkatkan PKS (Pengetahuan, Keterampilan dan Sikap) Petugas dan peternak penerima bantuan.Pelatihan Biogas bagi Petugas dan Peternak dilakukan pada tahun 2009. Pengembangan HMT dilakukan pada tahun 2009 pada kelompok Tani Nunulai Kelurahan Matabubu Kecamatan Poasia dan Kelompok Tani Lampareng Kelurahan Rahandouna dengan jenis HMT adalah rumput gajah. Pada Tahun 2010 bantuan HMT diberikan kepada Kelompok Tani Mendidoha Kelurahan Abeli Kecamatan Abeli yaitu rumput gajah.Pada tahun 2011 pengembangan HMT bantuan HMT diberikan kepada Kelompok Tani Mabullo siripa Kelurahan Baruga Kecamatan Baruga dengan jenis HMT yaitu rumput gajah.

Penjaringan Sapi Betina Produktif berjumlah 2 Paket yang terdapat di Kecamatan Poasia Kelurahan Matabubu Kelompok Tani Nunulai dan Kecamatan Abeli Kelurahan Petoaha Kelompok Tani Medulu Tahun 2011.
Pembangunan Instalasi Biogas mulai dilaksanakan pada tahun 2008 yang terdapat di Kelompok Tani Tunas Segar Kelurahan Rahandouna Kecamatan Poasia dan Kelompok Tani Meteulu Kelurahan Abeli dalam Kecamatan Puwatu masingmasing satu paket. Pada Tahun 2009 yang mendapat kegiatan ini pada Kelompok Tani Medulu, Kelurahan Watubangga Kecamatan Baruga dan Kelompok Tani Gersamata Kelurahan Baruga Kecamatan Baruga masing-masing satu paket. Pada tahun 2011 terdapat 8 Unit sebanyak 8 Kelompok Tani yaitu Kelompok Tani Puurai Kelurahan Puwatu Kecamatan Puwatu, Kelompok Tani Bina Mandiri Kelurahan Watulondo Kecamatan Puwatu, Kelompok Tani Uluwanggu, Tetemelewe, Tunas baru Kelurahan Baruga Kecamatan Baruga, Kelompok Tani Tunas Baru Kelurahan Anggoeya Kecamatan Poasia, dan Kelompok Tani Kaseiseha Kelurahan Matabubu Kecamatan Poasia.

Program pengendalian penyakit pada ternak dilakukan secara rutin enam bulan sekali setiap tahun seperti Vaksinasi SE (Septichaemia Epizootica) dan Antrax sedangkan pengobatan pada ternak dilaksanakan ketika ada laporan dari peternak dan PPL serta pengawasan lalu lintas ternak.

Kebijakan yang menopang pembangunan peternakan sapi potong di Kota Kendari adalah berupa peraturan, diantaranya:

a. Perda nomor 8 tahun 2003 tentang Retribusi pengawasan, penataan dan pengujian mutu hasil/bibit dan hasil pertanian sub sektor peternakan.

b. Perda nomor 3 tahun 2011 tentang retribusi RPH.

\section{G. Evaluasi}

Evaluasi program pengembangan sapi potong bantuan Dinas Pertanian Dan Kehutanan Kota Kendari dimaksudkan untuk mengetahui dengan pasti pencapaian hasil, kemajuan dan permasalahan dalam pelaksanaan program tersebut sehingga 
dapat dinilai dan dipelajari untuk perbaikan pelaksanaan program tersebut di masa yang akan datang.

$$
\text { Hasil evaluasi program }
$$

pengembangan sapi potong bantuan Dinas

Pertanian dan Kehutanan Kota Kendari sudah dilaksanakan sesuai dengan petunjuk teknis program pengembangan sapi potong sehingga layak untuk dilanjutkan.

\section{KESIMPULAN DAN SARAN}

\section{Kesimpulan}

Kesimpulan yang dapat diambil dari hasil penelitian ini adalah:

1. Manajemen pemeliharaan sapi potong yang dilakukan oleh kelompok penerima bantuan adalah kandang yang digunakan kandang kelompok dan pengendalian penyakit ternak dilakukan oleh PPL dan petugas peternakan.

2. Rata-rata Perkembangan ternak sapi bantuan tahun 24 ekor/tahun.

3. Permasalahan pengembangan ternak sapi potong meliputi lahan gembala sempit, pada musim kemarau HMT kurang, harga sapi berfluktuasi, penyakit ternak dan pencurian.

4. Hasil evaluasi program sudah dilaksanakan sesuai dengan petunjuk teknis program pengembangan sapi potong sehingga layak untuk dilanjutkan.

\section{Saran}

1. Perlu adannya pengembangan Hijauan Makanan Ternak (HMT) untuk mengantisipasi kekurangan HMT pada musim kemarau.

2. PPL dan Petugas Peternakan perlu lebih proaktif lagi untuk mengatasi penyakit ternak.

3. Kelompok tani penerima bantuan sebaiknya diprioritaskan kepada kelompok tani yang memiliki lahan penggembalaan yang luas untuk mengantisipasi lahan penggembalaan yang semakin sempit.

\section{DAFTAR PUSTAKA}

Abidin, Z. 2006. Penggemukan Sapi Potong. Agromedia Pustaka. Jakarta.

Dinas Pertanian \& Kehutanan Kota Kendari, 2009.Kota Kendari dalam Angka.Dinas Pertanian dan Kehutanan Kota Kendari.

Gerungan, 1986.Psikologi Sosial. Eresco, Bandung.

Gunawan dan Pamungkas, 1998.Sapi Bali Potensi, Produktivitas dan Nilai Ekonomi. Penerbit Kanasius. Yogyakarta.

Guntoro, 2002.Membudidayakan Sapi Bali. Penerbit Kanisius. Yogyakarta.

Parakkasi, 1998.Ilmu Nutrisi dan Makanan Ternak Ruminan.Penerbit Universitas Indonesia. Jakarta.

Sugeng, 2003. Sapi Potong. Penebar Swadaya. Jakarta.

Soekartawi, 2011.Ilmu usahatani dan penelitian untuk pengembangan petani kecil.Penerbit Universitas Indonesia. Jakarta. 